\title{
Olhares entrecruzados sobre as políticas e reformas recentes e seus efeitos sobre o trabalho e as práticas docentes
}

Intercrossing visions about politcs and recent reforms and their effects on teacher's work and pratices

Cecília Borges

Dalila Andrade Oliveira

Este dossiê foi organizado a partir da contribuição de diferentes pesquisadores, inseridos em distintos contextos nacionais, mas que se debruçam sobre uma mesma temática por ângulos diversos. A unidade temática deste dossiê - a regulação educativa e o trabalho docente - foi encontrada no esforço de realização de um simpósio ocorrido no âmbito do $30^{\circ}$ Colóquio Internacional de Educação Comparada promovido pela AFEC (Associação Francófona de Educação Comparada) na cidade de Lille, França, em junho de 2006. Tentando integrar categorias de análises comuns, ele apresenta resultados de pesquisas empíricas realizadas em diferentes contextos, notadamente, Canadá (Quebec), ${ }^{1}$ Brasil e países do continente europeu (Portugal, Bélgica e Suíça). O fenômeno de uma nova regulação, expressa nos movimentos de reformas educativas dos últimos anos, afetando radicalmente o trabalho dos docentes, segue uma tendência internacional. Por meio de pesquisas produzidas em diferentes realidades nacionais e em distintos continentes, observa-se que uma nova regulação educativa tem contribuído na reestruturação do trabalho docente. A confrontação dos resultados dessas pesquisas e o intercâmbio entre pesquisadores que têm se debruçado sobre essa questão, em que se ressaltam a contribuição do CRIFPE, da AFEC e da Rede Estrado, tem possibilitado uma perspectiva comparada desses estudos.

1 O Quebec, por suas particularidades lingüísticas, culturais, políticas e administrativas, é tomado aqui como "nação quebequense" no âmbito do Canadá. 
As pesquisas que abordam realidades nacionais são de grande validade e atualidade no âmbito da educação comparada, visto que contribuem para pôr em evidência as particularidades e características específicas de cada país, permitindo, contudo, que semelhanças e linhas de tendência sejam observadas. No caso específico da temática aqui tratada, esses estudos têm dado visibilidade às formas sob as quais uma nova regulação educativa vem sendo desenvolvida em diferentes contextos, sendo mais ou menos convergente em termos de sua lógica reguladora e mercantil, apropriada, tanto nos discursos como nas práticas, pelos agentes escolares.

Pretende-se aqui justamente trazer uma contribuição aos estudos no âmbito da educação comparada, particularmente aqueles que focalizam os sistemas educativos, o trabalho docente e as práticas escolares como objeto de relações de conflito. Expressando o cruzamento de diferentes olhares sobre o impacto das novas formas de regulação e organização dos sistemas educativos, os artigos aqui publicados demonstram que a escola em diferentes contextos nacionais permanece sendo um espaço de tensão revelada nas práticas de ensino e no trabalho docente. Nosso objetivo na organização do Simpósio que deu origem a este dossiê, e, conseqüentemente, à produção dos artigos aqui publicados, não foi de encontrar consensos ou uma visão unificadora que fosse representativa desse grupo de pesquisadores e formadores de professores. Ao contrário, buscou-se enfatizar as diferentes formas que assumem as transformações educativas atuais, atravessando as fronteiras nacionais, respeitando, contudo, as particularidades de cada país, dos estabelecimentos escolares, dos diferentes desenhos de organização escolar e de distintos perfis profissionais docentes.

Este dossiê expressa dois ângulos de análise complementares. Aborda os indicadores de uma nova regulação educativa presentes nas mudanças recentes observadas nos estabelecimentos escolares e nas políticas educativas de diferentes países, mais particularmente quanto à instauração de instrumentos e métodos de gestão e de expansão do ensino. Pretende, ainda, evidenciar estudos que tratam das repercussões destas mudanças sobre o trabalho docente, as práticas escolares, as condições de trabalho e de ensino de docentes e não docentes.

Quais mecanismos de gestão e de financiamento vêm sendo implantados nos diferentes países tanto do norte como do sul? Estes mecanismos asseguram uma gestão mais democrática e uma distribuição 
mais igualitária dos recursos para a educação? Quais instrumentos de avaliação são utilizados para medir a qualidade da educação? De que forma esses mecanismos de gestão e de financiamento, assim como os instrumentos de avaliação, alteram as condições de trabalho e autonomia docentes? Qual impacto as reformas educativas e dos currículos têm sobre a organização escolar e sobre as práticas profissionais dos docentes? Estes são alguns dos temas que abordaremos neste dossiê em distintos contextos educacionais.

Por esse motivo é que a análise comparada se apresenta atualmente como uma ferramenta essencial, permitindo confrontar diferentes realidades educativas a partir de uma abordagem na qual se estabelecem os contrastes e diferenças, as similitudes e convergências entre os distintos contextos nacionais, e mesmo continentais. A escola atual é confrontada com forças contraditórias oriundas dos níveis locais (comunidade, grupos de pressão, associações diversas etc.), nacionais (Estado, indústrias, sindicatos etc.) e transnacionais (globalização, regulação, competição, estandardização, mobilidade etc.). Estas pressões se conjugam por meio de processos de reformas educacionais, que expressam grandes contradições: igualdade e competição, desempenho individual e ênfase no trabalho coletivo, profissionalização e controle externo, novas demandas e compressão de recursos, ênfase na qualidade dos processos e visão quantitativa dos resultados, entre outras. Os artigos que compõem este dossiê procuram tratar tais questões à luz de experiências concretas.

Claude Lessard, professor da Universidade de Montreal, diretor do Labriprof-CRIFPE ${ }^{2}$ e titular de uma Cátedra de pesquisa do Conseil de Recherche en Sciences Humaines du Canadá (CRSH), Quebec, aborda três modos de regulação da educação: a burocracia estatal, a profissão e o mercado, particularmente a partir da noção de autonomia profissional presente nos discursos das associações profissionais e centrais sindicais canadenses e quebequenses. Explora as noções de responsabilização, prestação de contas, autonomia professoral em relação ao New Public Management, que, sem excluir a necessária autonomia dos professores, exige uma maior eficiência e performance em termos de resultados escolares.

2 Laboratoire de Recherche et d'Intervention Portant sur les Politiques et les Professions en Éducation (LABRIPROF) e Centre de Recherche Interuniversitaire sur la Formation et la Profession Enseignante (CRIFPE). 
Branka Cattonar, pesquisadora vinculada à Universidade de Louvan, na Bélgica, realizando atualmente um estágio de pós-doutoramento no CRIFPE, discute os efeitos e as transformações advindas dos novos modos de regulação sobre o trabalho dos diretores de escola de dez províncias canadenses. ${ }^{3}$ A autora demonstra como os diretores percebem as transformações ocorridas no seu trabalho considerando as novas responsabilidades dos estabelecimentos escolares em relação à comunidade, à organização e gestão coletiva, à "autonomização balizada" do pessoal docente e administrativo e às novas prescrições institucionais que dizem respeito à "liderança pedagógica" que devem assumir esses diretores. Sentindo-se interpelados pelas transformações escolares atuais, as quais, segundo eles, têm impactos importantes em sua função e no funcionamento da escola, os diretores apontam várias repercussões negativas destas transformações, permanecendo, contudo, otimistas em relação aos efeitos positivos que elas terão sobre as escolas. Apesar do aumento da sua carga de trabalho, eles expressam uma grande satisfação quanto a vários aspectos de sua função.

Marie-Claude Riopel, pesquisadora do CRIFPE, Quebec, apresenta o resultado de um estudo pan-canadense sobre as preocupações dos professores de escolas primárias e secundárias ${ }^{4}$ de três províncias (Quebec, Ontário, Colúmbia Britânica) em relação às políticas e reformas escolares recentes. A autora constata a preocupação dos professores em manter seus compromissos sociais e educativos, a fim de exercer sua função com profissionalismo e, ao mesmo tempo, adaptar-se às transformações profundas ocorridas em suas condições de trabalho resultantes da descentralização da educação, inscrita numa lógica de imputabilidade, de aumento das responsabilidades e das obrigações dos atores. Demonstra que esses profissionais são chamados a exercer uma maior autonomia nos seus estabelecimentos, mas submetendo-se a exigências de eficácia e restrições orçamentárias, políticas e também profissional.

3 Ontário, Quebec, Colúmbia Britânica, Alberta, Saskatchewan, Manitoba, Nova Escócia, Novo Brunswick, Terra Nova e Labrador, Ilha do Príncipe Eduardo e dos Territórios do Noroeste, do Yukon e do Nunavut.

$4 \quad$ Os artigos aqui publicados fazem referência a distintas formas de organização escolar e do ensino referentes a seus países de origem: Canadá e alguns países europeus. As pesquisas foram centradas na realidade escolar que corresponderia ao nível básico de ensino no Brasil. 
Cecília Borges, professora da Universidade de Montreal e pesquisadora associada ao CRIFPE, apresenta um estudo sobre a colaboração entre docentes de duas escolas secundárias quebequenses no contexto de implantação e experimentação do novo programa escolar. A partir de uma pesquisa de caráter qualitativo, colocando em evidência dois contextos distintos de apropriação e de implementação do novo programa, a autora analisa como um grupo de professores responde no seu cotidiano de trabalho às políticas educativas cujas orientações preconizam uma maior colaboração, coordenação, autonomia e responsabilização coletiva dos docentes pelo trabalho escolar. Focalizando tanto as condições que favorecem quanto os obstáculos que dificultam a emergência da colaboração, ressalta certas tensões subjacentes às exigências colaborativas no âmbito das novas formas de regulação do trabalho.

Abdeljalil Akkari, pesquisador sênior da HEP-Bejune, Suíça, propõe analisar a evolução do ensino secundário e sua forma escolar, destacando as lições oriundas das transferências de modelos dos países do Norte aos países do Sul. Se nos países do Norte, já faz algum tempo, o ensino secundário ocupa uma parcela importante dos sistemas educativos, nos países do Sul este nível de ensino está em franca expansão, notadamente porque, tendo por inspiração os modelos do Norte, crê-se que o ensino secundário contribuiria para o crescimento econômico. Neste contexto, o autor chama a atenção para as discrepâncias subjacentes à noção de transferência, assim como para as condições de formação dos docentes do ensino secundário. Em relação a estes, salienta o desajuste entre as novas competências exigidas pelos sistemas escolares na sociedade do conhecimento e as competências com que são "equipados" os professores do secundário após sua passagem pela formação universitária ou superior.

Por fim, Dalila Andrade Oliveira, professora da Universidade Federal de Minas Gerais e membro da coordenação da Rede Estrado, Brasil, aborda as conseqüências da nova regulação educativa sobre o trabalho docente no contexto latino-americano, particularmente na Argentina, no Brasil e no Chile. A autora evidencia como as novas formas de regulação repercutem na composição, na estrutura e na gestão das redes públicas de ensino, que buscam adequação ao novo contexto a partir de critérios de produtividade, eficácia, excelência e eficiência, segundo padrões internacionais. Procura mostrar, igualmente, como nos países sulamericanos, que partem de patamares de desenvolvimento educativo 
diferente daqueles da América do Norte e da Europa, as reformas educativas atuais que definem as relações de trabalho, a normalização da carreira, a remuneração, bem como a profissão e a identidade dos docentes assumem uma configuração particular, própria dos países em desenvolvimento.

Finalmente, gostaríamos de agradecer a cada um dos autores que participaram deste dossiê, por sua inestimável contribuição e profissionalismo, pelo respeito aos prazos e por terem assumido a tradução de seus textos para o português. Agradecemos também à equipe editorial da Educação em Revista, pela seriedade do seu trabalho e pela contribuição que prestam ao meio educacional. 